\title{
Cost Estimation of Fare-Free ADA Complementary Paratransit Service in Illinois
}

\author{
Paul Metaxatos and Lise Dirks \\ University of Illinois at Chicago
}

\begin{abstract}
Instituting a free fare for ADA complementary paratransit service in the state of Illinois will expectedly increase the demand and associated costs of providing the specialized service. This paper proposes a method to estimate such demand and cost increases. Our results show an estimated average increase in annual ADA trips between 121 and 171 percent in the Chicago area. Given previous industry free-ride experiments, the latent demand exhibited by the large number of persons with disabilities living within $3 / 4$ mile of a fixed route, and the expected diversion of wheelchair riders currently using fixed routes, we believe it is not unreasonable to expect increases in ridership approaching 100 percent. Compared to the (2007\$) baseline total statewide cost of $\$ 99.3$ million, the estimated cost due to increased demand would be between $\$ 123.9$ and $\$ 160.6$ million.

\section{Introduction}

The Americans with Disabilities Act of 1990 (ADA) created a requirement for complementary paratransit service for all public transit agencies that provide fixed-route service. Complementary paratransit service is intended to complement the fixed-route service and serve individuals who, because of their disabilities, are unable to use the fixed-route transit system. The service must operate on the same days and times of service within $3 / 4$ mile of the fixed route, and fares cannot exceed
\end{abstract}


twice the base adult fare. In fulfilling their ADA obligations, transit operators have a responsibility to consider current and probable future demand for complementary paratransit service and to plan and budget to meet all of the expected demand (Koffman et al. 2007).

In January 2008, then Illinois Governor Rod Blagojevich used his amendatory veto power when approving the state's transit funding legislation to allow persons over the age of 65 to ride the state's transit systems free. This controversial decision resulted in a loss of revenue to the transit providers in the state. The Illinois Department of Transportation directed the Urban Transportation Center at the University of Illinois to undertake a demand estimate of the ridership and financial impact if ADA Special Paratransit Services were made free. Neither the governor nor the Illinois General Assembly have taken any action to make ADA Special Services free, although they did approve a free-ride program for persons with disabilities who use fixed-route and rail transit services.

Instituting a free fare for ADA complementary paratransit service in the state of Illinois will expectedly increase the demand and the associated costs of providing the specialized service. This paper proposes a method to estimate such demand and cost increases using statistical analysis in combination with industry experience that acknowledges that there are several factors affecting the demand for ADA special services. Overall, these factors that tend to magnify the demand resulting from free fares are discussed below.

- Growth of disabled population. The Census predicts an increase in the disabled population in the Chicago region over a 10 -year period of 8.7 percent (RTA 2007).

- Low-income disabled population. The percent of low-income persons with disabilities is higher than the percentage of low income of the general population. While 30 percent of the Chicago region is low-income, a survey by the Chicago Transit Authority (CTA) in 1998 found 55 percent of the disabled population to be low-income (RTA 2007; Spielberg and Pratt 2004).

- Percentage of population with disabilities. The percentage of the population defined by the Census as disabled is 16 percent in the Chicago region and 16.6 percent downstate (see Table 7).

- Normal growth in number of trips. The Regional ADA Plan by the Regional Transit Authority (RTA) projected the increase in the number of rides of ADA 
special services of 10 percent annually in the city of Chicago and 6 percent annually in the suburbs (RTA, CTA, and Pace 2006).

- The relationship with fixed-route fares. The fixed-route fare for people with disabilities is one half the base adult fare ( $\$ 0.85$ for CTA, $\$ 0.75$ for Pace regular reduced, and $\$ 0.60$ for Pace local reduced). By reducing the paratransit fare to free, there will be a diversion of riders from fixed routes to paratransit. In 2006, the last full year of data on lift usage by the CTA, there were 305,705 lift usages reported (CTA 2011). In 2007, Pace (the suburban Chicago transit provider) carried 25,509 lift trips on its fixed-route buses (Pace 2007). Many of these trips would be diverted to paratransit if the paratransit fare became free. In some cases, transit agencies may reduce the fixed-route fare to free in order to divert paratransit riders to fixed-route. In any case, it is expected that the fixed-route fare would be free if the paratransit fare were to be made free for riders with disabilities.

- Increased capacity will result in more subscriptions. Subscription services cannot exceed 50 percent capacity during any service hour (RTA, CTA and Pace 2006) - unless there is non-subscription capacity (U.S. GPO 2011). If capacity is increased as a result of free fares, it will also increase the capacity for subscription services, which have a demand in excess of single trips.

- Fixed-route free fares greatly encourage discretionary trips. Experience with free fares for fixed-route and dial-a-ride has resulted in an increase in demand for social and discretionary trips, including "joy riding," for example, just to get out of the house (Perone and Volinski 2003). Most of the current ADA trips are for medical and work trips; however, institution of a free fare may increase discretionary ADA trips (Spielberg and Pratt 2004).

- Free fares may encourage "dumping" by other social service agencies. Social service agencies would have a financial incentive to encourage clients to utilize the free service in lieu of the agency-provided services (West 1996).

\section{Industry Experience}

\section{Fixed Route Transit Fare Elasticity}

Traditional fixed-route transit demand elasticity relies on the "Simpson \& Curtin" demand elasticity - shrinkage ratio, to be more accurate-of -0.33 , meaning for every 3 percent increase in fare, there will be a corresponding 1 percent loss of ridership (McCollom and Pratt 2004). An informative discussion about various elasticity measures for transportation demand is provided elsewhere (Pratt 2000). 
The American Public Transportation Association (APTA) has done further analysis of fixed bus demand and developed a range of elasticity from - 0.18 to -0.43 depending on peak or off-peak service and the size of the metropolitan area. This demand elasticity has also been used to predict ridership when fares are reduced. There is no agreement in the industry that the elasticity for fare increases is also valid for fare reductions. However, using this method to predict free fares, a 100 percent decrease in fares would result in an increase in fixed-route ridership between 18 and 43 percent depending on size of metro area and whether it is peak or off-peak service (APTA 1991).

\section{Non-ADA Paratransit Fare Elasticity}

There has been fare elasticity developed for paratransit that closely resembles fixed route elasticity:

- Norfolk, Virginia, dial-a-ride showed a range of elasticity of -0.16 to -0.64 (Spielberg and Pratt 2004)

- Ann Arbor, Michigan, dial-a-ride showed -0.44 (Spielberg and Pratt 2004)

- Levittown, New York, shared ride taxi showed -0.54 (Spielberg and Pratt 2004)

- AppalCART (Boone County), North Carolina, free-fare door-to-door paratransit service since 2005, showed -0.59 the first year and -0.13 the second year (AppalCart 2011)

Using the elasticity from the examples above, and assuming that the empirical results above are transferable across cities, a reduction in fare to zero would result in a paratransit ridership range increase between 16 and 64 percent.

\section{Free Fare Demonstrations}

There have been free fare demonstrations of fixed-route services, where fares were reduced 100 percent and made free to the general public, which have resulted in measurable increases in ridership. Denver made off-peak fares free and experienced an increase in total ridership of 36 percent (Doxsey and Spear 1981). Trenton, New Jersey, obtained an increase in total ridership of 16 percent (Studenmund and Connor 1982). Austin, Texas, experienced a total ridership increase of 75 percent but adjusted the result from free fares to 10 percent due to the existence of other factors, including increases in service (Perone and Volinski 2003). The AppalCART paratransit free-fare example above showed an increase in total ridership of 59 percent. Other literature suggests anticipated increases in total ridership resulting from free fares of approximately 50 percent (Perone and Volinski 2003). 


\section{ADA Trip Rates Per Capita}

Spielberg and Pratt (2004) reported annual trips per capita in cities with ADA fares less than $\$ 0.50$ at a rate roughly twice the rate as cities with fares of $\$ 1.00$ or more.

\section{TCRP Demand Curve}

A recent report (Koffman et al. 2007) on ADA complementary paratransit demand estimation predicts demand for service by ADA-eligible individuals, for trips within $3 / 4$ mile of fixed-route service, based on reservations taken from 1 to 14 days in advance. Demand is predicted for service that is not capacity-constrained by significant numbers of denials, unreliable service, or excessive telephone wait times to reach a reservations agent. Statistical models were developed based on data from 28 representative systems. To the extent possible, demand is predicted only for trips that ADA-eligible individuals are unable to make by fixed-route service. The methodology gives predicted annual ridership and annual ridership per capita, as well as confidence limits for these statistics. The demand estimates are based on the following six factors:

1. ADA service area population: total population according to the 2000 U.S. Census for the actual area served by ADA paratransit. Depending on service policies, this may be just the area $3 / 4$ mile around fixed-route service or a larger area.

2. Base Fare: the full cash fare for an ADA paratransit trip before any discounts for advance purchase or use of a monthly pass, and before adding any zone charges.

3. The percent of applicants found conditionally eligible: $100 \times$ (number of people found eligible with conditions) $\div$ (number of people who apply for ADA paratransit eligibility).

4. Conditional trip determination: 1 if trip-by-trip determination based on conditions of eligibility is done, 0 otherwise.

5. Percent below the poverty rate: $100 \times$ ( number of people in households with incomes below poverty rate in area actually served by ADA paratransit as reported in the 2000 U.S. census) $\div$ (ADA service area population from \#1 above).

6. Effective on-time window: the total variation in pick-up time, before or after the last time that was given to the customer, before the trip is no longer counted as being "on-time." For example, if a vehicle is considered late beginning 20 minutes after the promised time, but customers are expected to be 
ready 10 minutes before the promised time, then the "effective window" is 30 minutes. Similarly, if pick-up times can be changed by up to 10 minutes without informing the customer, then the effective window may need to be adjusted.

Table 1 presents elasticities for system changes of one percent.

Table 1. TCRP Report 119 Elasticities

\begin{tabular}{|c|c|c|c|}
\hline Variable & Elasticity & Factor & Interpretation \\
\hline $\begin{array}{l}\text { Base Fare } \\
\text { Factor }\end{array}$ & -0.77 & & A $1 \%$ higher base fare corresponds to $0.77 \%$ less demand. \\
\hline \multirow{2}{*}{$\begin{array}{l}\text { Percent } \\
\text { Conditionally } \\
\text { Eligible }\end{array}$} & $\begin{array}{l}-0.29 \\
\text { at the } \\
\text { mean }\end{array}$ & & $\begin{array}{l}\text { A } 1 \% \text { higher percent found conditionally eligible com- } \\
\text { pared to the mean value of } 21 \% \text { corresponds to } 0.29 \% \text { less } \\
\text { demand. }\end{array}$ \\
\hline & & 1.39 & $\begin{array}{l}\text { A } 1 \% \text { greater percentage of applicants found condition- } \\
\text { ally eligible corresponds to } 1.39 \% \text { less demand. }\end{array}$ \\
\hline $\begin{array}{l}\text { Conditional } \\
\text { Trip } \\
\text { Screening }\end{array}$ & & $48 \%$ & $\begin{array}{l}\text { Systems that use conditional trip screening have } 48 \% \\
\text { lower demand than other systems. }\end{array}$ \\
\hline \multirow{2}{*}{$\begin{array}{l}\text { Percent } \\
\text { Below } \\
\text { Poverty }\end{array}$} & $\begin{array}{l}-0.90 \\
\text { at the } \\
\text { mean }\end{array}$ & & $\begin{array}{l}\text { A } 1 \% \text { higher poverty rate compared to the mean value of } \\
13 \% \text { corresponds to } 6.6 \% \text { less demand. }\end{array}$ \\
\hline & & -6.6 & $\begin{array}{l}\text { A } 1 \% \text { higher percentage of the population below the } \\
\text { poverty level corresponds to } 6.6 \% \text { less demand. }\end{array}$ \\
\hline $\begin{array}{l}\text { Effective } \\
\text { Window }\end{array}$ & -0.72 & & $\begin{array}{l}\text { A } 1 \% \text { wider effective window corresponds to } 0.72 \% \text { less } \\
\text { demand. }\end{array}$ \\
\hline
\end{tabular}

Source: TCRP Report 119

In the same report, the formula for predicting demand is as follows:

ADA Paratransit Trips per Year $=($ Total ADA Service Area Population $) * 3.463$

* (Base Fare) $)^{-0.772 *} \exp (1.385 \times$ (Percent of Applicants Found Conditionally

Eligible/100)) * $\exp (-0.662 \times$ (Conditional Trip Determination) $) * \exp (-6.633 \times$

(Percent of Population below Poverty/100)) * (Effective On-time Window) $)^{-0.722}$

Based on the exponent of -0.772 in the formula above, the price sensitivity of demand for ADA paratransit trips due to changes in base fare price can be seen in Figure 1. A decrease in base fare from $\$ 3.50$ to $\$ 1.00$ increases the demand for trips by 100 percent. Another $\$ 0.50$ drop in the base fare and the demand increases another 71 percent. The next base fare drop to $\$ 0.25$ brings the demand up another 121 percent. 


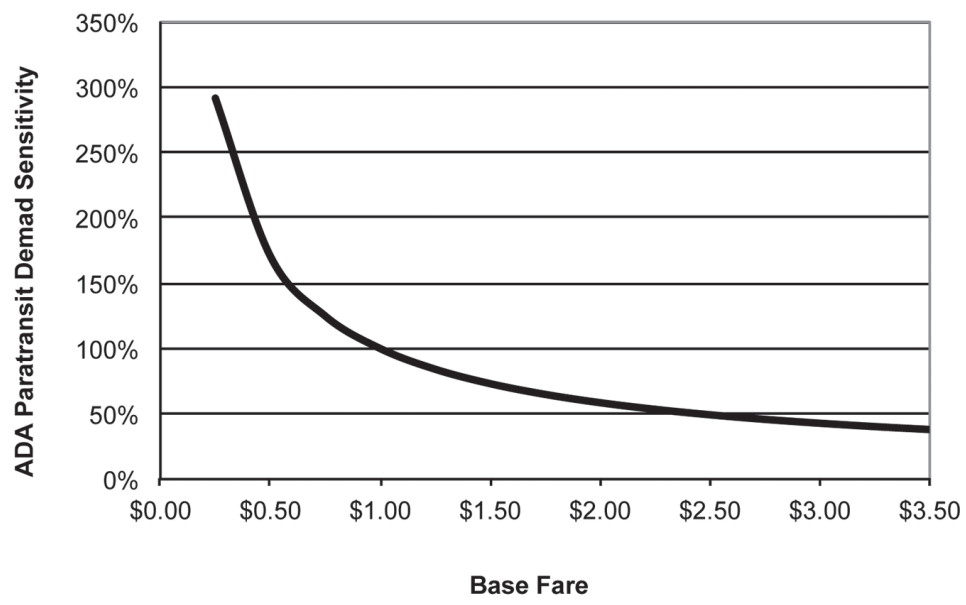

Figure 1. TCRP Report 119 demand curve

The implication of the TCRP demand curve is that as base fare closes in the neighborhood of a fare-free policy, the ADA demand for paratransit trips becomes "infinitely large," which is obviously absurd given the supply constraints. Besides, it would be difficult to justify the huge number of eligible paratransit ADA riders or the dramatic change in trip making corresponding to such "infinite" demand for trips.

The veracity of this argument can be readily demonstrated by inserting different values in the spreadsheet tool that accompanies the TCRP report (onlinepubs.trb. org/onlinepubs/tcrp/tcrp_rpt_119Tool.xls). For example, in an area with 1,000,000 population, the predicted annual ADA ridership is 18,581,500 trips for a fare-free policy (actually, the fare was set to $\$ 0.01$ because the TCRP model is not defined at $\$ 0$ fare), while doubling the area's population increases the ADA annual trips to $37,162,999$, which is almost 10 times the number of trips the New York City Transit Authority currently provides.

Clearly, the TCRP demand curve as presented cannot be used to estimate the impact of fare-free policies. In fairness, that was not the purpose of the TCRP demand curve, the estimation of which was partially based on a base fare range between $\$ 0.50$ and $\$ 3.50$ among the 28 transit properties studied.

\section{TCRP Demand Curve Adjustment}

Given the need to obtain a reasonable measure to assess the demand for trips due to a fare-free policy, we decided to adjust the previous TCRP demand curve. Three reasons led us to such a decision: (a) uncertainty regarding availability of local 
data; (b) the adjustment would be based on the same data that TCRP used for the demand curve described above; and (c) a successful adjustment would complement the TCRP model and assist other transit professionals in policy assessment.

The TCRP demand curve adjustment was made through the estimation of a linear regression model that used the same independent variables as the TCRP model. The dependent variable in our model is the trip rate (instead of the number of trips in the TCRP model). The trip rate is defined as the number of ADA paratransit trips for each transit property in the data set divided by the respective ADA service area population. We chose the trip rate (instead of the number of trips in the TCRP report) to account for the large differences in total population in the areas of operation of the 28 transit properties in the data.

The data were obtained from the spreadsheet tool (onlinepubs.trb.org/online pubs/tcrp/tcrp_rpt_119Tool.xls) that accompanies the TCRP Report 119. The data set consists of 28 data points that contain information from the transit properties surveyed in the TCRP report. Summary statistics for the variables in the model can be seen in Table 2. The definitions of the variables are the same as in the TCRP report and were discussed earlier.

Table 2. Summary Statistics for Variables Used in Model

\begin{tabular}{|c|c|c|c|c|}
\hline Variable & Mean & Std. Dev. & Minimum & Maximum \\
\hline \multicolumn{5}{|l|}{ Dependent } \\
\hline Trip Rate & 0.59 & 0.48 & 0.07 & 1.85 \\
\hline \multicolumn{5}{|l|}{ Independent } \\
\hline Base Fare (\$) & 1.81 & 0.83 & 0.50 & 3.50 \\
\hline \% Eligibility & $21 \%$ & $22 \%$ & $0 \%$ & $79 \%$ \\
\hline Cond. Eligibility & $46 \%$ & $50 \%$ & $0 \%$ & $100 \%$ \\
\hline$\%$ Poverty & $13.5 \%$ & $5.7 \%$ & $4.6 \%$ & $32.9 \%$ \\
\hline On Time (min.) & 30.35 & 9.99 & 10 & 60 \\
\hline
\end{tabular}

The procedure we used for the model estimation is a least-squares procedure. Upon running the regression model and obtaining regression diagnostics, it became clear we needed to focus on two issues: (a) heteroscedasticity and (b) outliers and influential observations. The first issue violates one of the conditions that, if they hold, assure us that least squares is a good procedure. The treatment of both issues as discussed below follows guidelines found in statistical textbooks (e.g., Sen and Srivastava 1990). 
We detected heteroscedasticity upon plotting the regression residuals against the predicted values. We decided to weight the regression using the inverse of the predicted value as the weight as recommended in statistical practice (Sen and Srivastava 1990). We ran the least-squares procedure for several iterations each time using the weights form the previous iteration. Every time, we plotted the newly-obtained (weighted) residuals against the predicted values to verify that heteroscedasticity was decreasing. After seven iterations, the weights for each observation appeared to stabilize, and it seemed, at least momentarily, that we had obtained a good model.

On second inspection, however, we realized we had a problem with the second issue, outliers and influential observations. One transit property in particular, Hillsborough Area Regional Transit (HART), appeared to be very influential (in the order of two to five times compared to other properties). Further investigation revealed that this property had, by far, the lowest trip rate and the highest effective on-time window of all properties in the data. Indeed, HART's trip rate was less than 0.08 trips per capita, while the next lowest trip rate was 0.10 trips per capita. Moreover, HART's effective on-time window was 60 minutes, which was 15 minutes greater than the next lower value. These observations led us to introduce an indicator variable (D1) in the model that took the value of 1 if the effective on-line window was more than $\mathbf{4 5}$ minutes and the value of zero, otherwise. This took care of the influence of the HART property and improved the fit of the model. No other observation stood out based on regression diagnostics (studentized residuals, leverage, DFFITS, and DFBETAS as recommended in Sen and Srivastava 1990). We also obtained collinearity diagnostics (tolerance, variance inflation factors, condition numbers, and variance proportion factors) and verified the absence of multicollinearity from the model (Sen and Srivastava 1990). The final estimated model is shown in Table 3.

Table 3. Regression Results

\begin{tabular}{|l|c|c|c|c|c|c|}
\hline Variable & $\begin{array}{c}\text { Parameter } \\
\text { Estimate }\end{array}$ & \multicolumn{2}{|c|}{$\begin{array}{c}\text { 90\% Confidence Limits } \\
\text { of Parameter Estimate }\end{array}$} & $\begin{array}{c}\text { Standard } \\
\text { Error }\end{array}$ & t-Value & Pr $>|\mathbf{t}|$ \\
\hline Intercept & 2.66 & 1.82 & 3.49 & 0.48 & 5.47 & $<0.01$ \\
\hline Base Fare & -0.31 & -0.44 & -0.18 & 0.07 & -4.07 & $<0.01$ \\
\hline \% Eligib. & -0.71 & -1.05 & -0.37 & 0.19 & -3.62 & $<0.01$ \\
\hline Cond. Elig. & -0.43 & -0.63 & -0.24 & 0.11 & -3.95 & $<0.01$ \\
\hline Pct. Poverty & -4.30 & -6.42 & -2.17 & 1.23 & -3.48 & $<0.01$ \\
\hline On Time & -0.01 & -0.03 & 0.005 & 0.00 & -2.42 & $<0.05$ \\
\hline D1 & 0.86 & 0.30 & 1.43 & 0.32 & 2.65 & $<0.05$ \\
\hline
\end{tabular}

$\mathrm{R}^{2}=0.67, s=0.13$ 
All of the coefficients are significant at the $95 \%$ confidence level. The model has a reasonable goodness of fit as measured by R-squared with 67 percent of variation in the ADA paratransit trip rate explained. The following observations can be made by examining the results for each variable in the model:

- The significant intercept term gives the predicted trip rate when all other variables are set to zero. This has no practical meaning.

- The fare coefficient implies that every drop in the base fare by $\$ 1$ would increase ridership by 0.31 trips per capita (all other variables are held constant).

- Ridership decreases with the percent of applicants found conditionally ADA-eligible. Systems that have higher percentages of applicants found conditionally-eligible (rather than fully-eligible or eligible without conditions) have lower demand.

- Conditional trip screening reduces paratransit usage. Given that this is a 0/1 variable, the coefficient of this variable would indicate that systems that use conditional trip screening have 43 percent less ridership than systems that do not use conditional trip screening. A possible explanation of this is that riders reduce their requests based on the conditions they have been given or based on experiences in which they have requested trips and been turned down for trip-specific eligibility reasons. Another reason might be that systems that use conditional trip screening also have more rigorous eligibility screening practices in general in ways not captured by the percentage of applicants found fully or conditionally eligible (Koffman 2007).

- Trip making decreases at higher poverty rates. Recall that this variable measures the total area-wide poverty rate, not the rate of poverty among people with disabilities. In general, people with higher income travel more than people with lower income. It is also likely that communities with higher poverty rates will have fewer available activities that generate travel than more affluent communities.

- Longer effective windows reduce trip making, but its effect is not pronounced.

\section{Implications of Model Results for a Free Fare Policy}

The parameter estimate of the base fare is -0.31 with a 90 percent confidence interval of $[-0.44,-0.18]$. As a result, and assuming the other variables in the model are held constant, reducing the base fare from $\$ 3$ to $\$ 0$ would increase the average trip 
rate by ( $3 \times 0.31=0.93$ trips per capita) or a percentage increase (at the mean trip rate of 0.59 in Table 2$)$ of $([0.59+0.93] / 0.59=257 \%)$. Moreover, 90 percent of the time, the trip rate is expected to increase (at the mean) between 191 and 323 percent. With the additional assumption that the total population in the service area will remain unchanged in the short term, the findings regarding trip rates translate directly into the demand for ADA complementary paratransit trips.

Note that the predicted trip rate increase does not necessarily mean that paratransit riders would start making more trips enticed by the free-fare policy (although this should not be excluded at least to some extent). Such an increase along with increases due to latent demand and demand shift from fixed-route services (as mentioned earlier in this paper) would increase the total number of ADA paratransit trips. As a result, given that the total population (the denominator) remains fixed, the trips-per-capita value increases.

It would also be worth noting that factors such as inflation and fare policy changes in the future could affect the calculus of the cost impacts of a free-fare policy. Additionally, a potential demand shift from fixed-route services could also affect such cost impacts. These factors could not be addressed in this paper. Moreover, using an average cost per trip as the basis for estimating the predicted costs over the entire spectrum of anticipated demand increase may prove to be a high-end estimate of total costs because of economies of scale in the provision of free-fare services.

Table 4 summarizes the impact of the zero-fare policy for different parts of the Chicago region. It is important to note that such impacts can be reasonably anticipated under two provisions:

- Pace ADA paratransit operations are similar (in terms of eligibility and effective on-time window) from those in the transit agencies included in the data set we analyzed. Indeed, the RTA indicates 100 percent eligibility and a 20-minute on-time window (RTA 2006), which is within the ranges reported in TCRP Report 119.

- The percentage of people in households with incomes below the poverty rate in the Chicago area is similar to those from other parts of the country in the data set analyzed. Indeed, the poverty rate in Illinois ranges from 4 to 19 percent compared to the 3 to 33 percent range reported in TCRP Report 119. 
Table 4. Expected Demand Increase in Chicago Area

\begin{tabular}{|l|c|c|c|}
\hline Region/County & $\begin{array}{c}\text { Current } \\
\text { Fare }\end{array}$ & $\begin{array}{c}\text { Expected Annual } \\
\text { Demand Increase }\end{array}$ & $\begin{array}{c}\text { Range of Annual Demand } \\
\text { Increase (90\% Certainty) }\end{array}$ \\
\hline Cook* \& DuPage Counties & $\$ 3.00$ & $150 \%$ & $129 \%$ to $171 \%$ \\
\hline $\begin{array}{l}\text { Lake, Kane, Will \& McHenry } \\
\text { Counties }\end{array}$ & $\$ 2.50$ & $141 \%$ & $124 \%$ to $159 \%$ \\
\hline City of Chicago & $\$ 2.25$ & $137 \%$ & $121 \%$ to $153 \%$ \\
\hline
\end{tabular}

*excluding the City of Chicago

In the Chicago region, the current ADA trip rate reported by Pace is 1.85 . Considering the fare differential in separate parts of the region, the range of impacts on demand of a free-fare policy is reported in Table 4. Note that the larger the drop from a current base-fare value to a zero-fare policy, the larger the range (uncertainty) of the impact on the demand for ADA trips.

Perhaps a few words of caution are in order here. The particular model specification does not prevent estimating negative trip rates for certain combinations of the independent factors. Fortunately, this was not the case with the data analyzed; all predicted rates were positive, with 26 out of 28 trip rates within the prediction interval. In addition, many factors that could potentially affect the ADA demand are not included in the model and, therefore, their impact should be corroborated from other sources. Meanwhile, the model above is a reasonable approach to quantify the impacts of a zero-fare policy on ADA paratransit demand.

\section{Cost Estimation of a Free Fare Policy}

\section{Average Cost Per Trip}

The cost to provide origin-to-destination ADA special services varies with the type of service provided, vehicle characteristics, the vendor, and the type of contract. In northeastern Illinois, Pace contracts for service in both the city and suburbs. The majority of the systems in the rest of the state contract with private vendors and, in some cases, in conjunction with their dial-a-ride for the general public and older adults. Table 5 shows the average cost per trip as reported by the transit agencies for 2007. Note that the suburban cost in Table 5 includes a contract cost of $\$ 31.16$ per trip plus an imputed capital cost of a paratransit vehicle of $\$ 0.94$ per trip. 
Table 5. Average Cost per ADA Trip

\begin{tabular}{|l|c|}
\hline Region & Cost \\
\hline City of Chicago (Pace) & $\$ 32.35$ \\
\hline Suburban Chicago (Pace) & $\$ 32.10$ \\
\hline Downstate (average) & $\$ 26.43$ \\
\hline
\end{tabular}

In addition, the cited costs are historical costs for 2007 through November 2011 and, depending on contract length, could increase in the future. For city of Chicago service, the cost of $\$ 32.35$ per trip was based on contracts in which vendors were paid on a per-trip basis. This practice has now changed to an hourly basis. If the number of trips per hour does not meet expectations, the costs could exceed the historical number depending on the efficiency experienced.

\section{Estimation of Market Size for New Riders}

We estimated the market for new riders potentially entering the system given a zero fare policy for ADA services. According to the Census 2000, Table 6 shows the estimated number of persons with disabilities, the estimated number of persons who are ADA-eligible, and the total number of certified ADA riders in the six-county region (RTA 2007; Perone 2002). The National Institute on Disability and Rehabilitation Research estimates that 20 percent of persons with disabilities use mobility devices (Kaye et al. 2000). Based on this statistic, we estimated that a minimum of 20 percent of the disabled population within the $3 / 4$-mile buffer is ADA eligible. In the state of Illinois, according to transit agency certification records, only 18.7 percent of eligible persons with disabilities within $3 / 4$ mile of a fixed-route service are certified, which is evidence of a great deal of latent demand.

Table 6. Demographic Information

\begin{tabular}{|l|c|c|c|c|}
\hline Region & $\begin{array}{c}\text { Disabled* } \\
\text { Population }\end{array}$ & $\begin{array}{c}\text { Disabled within } \\
\text { 3/4 Mile Buffer }\end{array}$ & $\begin{array}{c}\text { Estimated ADA } \\
\text { Eligible** }\end{array}$ & Certified*** \\
\hline Chicago & 604,602 & 604,602 & 120,920 & - \\
\hline Suburban Cook & 368,956 & 368,353 & 73,671 & - \\
\hline Collar Counties & 318,183 & 291,519 & 58,304 & - \\
\hline Chicago Region & $1,291,741$ & $1,264,474$ & 252,895 & 42,038 \\
\hline Downstate & 707,976 & 314,759 & 62,952 & 14,421 \\
\hline Total & $1,999,717$ & $1,579,233$ & 315,847 & 56,459 \\
\hline
\end{tabular}

*Disabled populations are estimated from Census SF3 data

** National Institute on Disability and Rehabilitation Research (Kaye et al. 2000)

***Transit Agency Records 
The estimates on the disabled population were obtained using a GIS process to identify populations within the $3 / 4$-mile fixed-route service area. The results shown in Table 6 are based on the assumption that all of Chicago would be included in the ADA service area. We used GIS coverage for Pace fixed routes and Metra stations in order to determine the 3/4-mile buffer that defines the ADA service area and to estimate the number of persons with disabilities from Census tract data. Note that Metra, and all other commuter rail systems, is not required to operate complementary paratransit systems under the 1990 ADA. However, Metra is providing a similar P-8 shuttle service (see http://metrarail.com/metra/en/home/utility_landing/riding_metra/accessibility.html) and, therefore, the ADA eligible figures in Table 6 can be thought of as an "upper bound" estimate.

For the remainder of the state, we obtained most of the transit districts' GIS coverage for the fixed-route service areas and identified the needed ADA service area and Census data using the $3 / 4$-mile rule. In the absence of digital service area maps, we used agency maps of the transit system to identify Census tracts within the ADA service area. Only one agency, the River Valley Transit District, did not make a system map available. In that case, we selected Census tracts for municipalities within the service area of the River Valley fixed-route service.

Note that the GIS process of selecting Census tracts to be included in the ADA service areas is not an exact process. Some Census tracts are included when they only partially intersect the $3 / 4$-mile buffer. We did not attempt to distribute the data between tract areas within and outside of the buffer areas. As a result, inaccuracies may still persist due to this spatial overlap, combined with the fact that we are using sample data.

Table 7 shows our estimates for different population groups in respective ADA service areas (comprising portions of Census tracts) as well as respective figures for all Census tracts (in italics). It is evident that while the two areas coincide in the city of Chicago, the ADA service area is substantially smaller within Census tracts in the rural parts of the state.

We also collected ADA service data from non-Chicago-area transit districts. Our request included data on ridership, number of persons certified, turndown rates, fares, and costs of service. While details are shown elsewhere (Dijohn et al. 2008), based on these data, we estimated the following: (a) a weighted (by each district's annual ADA trips) average full cash fare (no discounts or monthly passes) is $\$ 2.03$; (b) a weighted (by each district's annual ADA trips) average cost per ADA trip is 
Table 7. ADA Service Area Census Data (All Census Tracts)

\begin{tabular}{|c|c|c|c|c|c|c|}
\hline Population & $\begin{array}{l}\text { City of } \\
\text { Chicago }\end{array}$ & $\begin{array}{c}\text { Suburban } \\
\text { Cook }\end{array}$ & $\begin{array}{l}\text { Collar } \\
\text { Counties }\end{array}$ & $\begin{array}{l}\text { Chicago } \\
\text { Region }\end{array}$ & Downstate & $\begin{array}{l}\text { State } \\
\text { Totals }\end{array}$ \\
\hline \multirow{2}{*}{ Total } & $2,895,668$ & $2,475,817$ & $2,444,409$ & $7,815,894$ & $1,896,434$ & $9,712,328$ \\
\hline & $2,895,668$ & $2,481,073$ & $2,714,979$ & $8,091,720$ & $4,327,573$ & $12,419,293$ \\
\hline \multirow{2}{*}{ With disabilities } & & 368,353 & 291,519 & $1,264,474$ & 314,759 & $1,579,233$ \\
\hline & 4,602 & 368,956 & 318,183 & $1,291,741$ & 707,976 & $1,999,717$ \\
\hline \multirow{2}{*}{$\begin{array}{l}\text { With disabilities, } \\
65+\end{array}$} & 7,386 & 9,542 & 72,390 & 329,318 & 97,576 & 426,894 \\
\hline & 7,386 & 119,620 & 78,612 & 335,618 & 238,260 & 573,878 \\
\hline \multirow{2}{*}{ In poverty } & 556,741 & 156,235 & 121,040 & 834,016 & 226,125 & $1,060,141$ \\
\hline & & & 128,135 & 841,175 & & $1,291,958$ \\
\hline \multirow{2}{*}{$65+$} & 299,368 & 330,815 & 218,270 & 848,453 & 258,201 & $1,106,654$ \\
\hline & 299,368 & 331,084 & 238,566 & 869,018 & 629,911 & $1,498,929$ \\
\hline \multirow{2}{*}{$\begin{array}{l}\text { Unemployed } \\
\text { with disabilities }\end{array}$} & 116,445 & 76,790 & 71,225 & 264,460 & 59,810 & 324,270 \\
\hline & 116,445 & 76,966 & 78,294 & 271,705 & 131,482 & 403,187 \\
\hline \multirow{2}{*}{$65+$, in poverty } & & & & 71,698 & 17,999 & 89,697 \\
\hline & 44,683 & 17,340 & 10,444 & 72,467 & 45,464 & 117,931 \\
\hline \multirow{2}{*}{ Sensory disability } & 84,465 & 64,156 & 47,922 & 196,543 & 62,847 & 259,390 \\
\hline & 84,465 & 64,214 & 52,673 & 201,352 & 150,117 & 351,469 \\
\hline \multirow{2}{*}{ Physical disability } & 217,751 & 148,352 & 104,911 & 471,014 & 142,038 & 613,052 \\
\hline & & 148,546 & 115,480 & 481,777 & 332,577 & 814,354 \\
\hline \multirow{2}{*}{ Mental disability } & 132,959 & 77,633 & 64,821 & 275,413 & 84,096 & 359,509 \\
\hline & 132,959 & 77,787 & 71,036 & 281,782 & 184,506 & 466,288 \\
\hline \multirow{2}{*}{ Self-Care disability } & 86,623 & 50,126 & 35,599 & 172,348 & 43,933 & 216,281 \\
\hline & 86,623 & 50,152 & 38,938 & 175,713 & 100,792 & 276,505 \\
\hline \multirow{2}{*}{$\begin{array}{l}\text { Out-of-home } \\
\text { disability }\end{array}$} & 274,961 & 148,514 & 105,571 & 529,046 & 105,049 & 634,095 \\
\hline & 274,961 & 148,685 & 114,275 & 537,921 & 236,166 & 774,087 \\
\hline \multirow{2}{*}{$\begin{array}{l}\text { Employment } \\
\text { disability }\end{array}$} & 287,094 & 156,547 & 135,355 & 578,996 & 121,909 & 700,905 \\
\hline & 287,094 & 156,836 & 146,997 & 590,927 & 265,153 & 856,080 \\
\hline
\end{tabular}

\$26.43. Using this information as well that in Tables 4 and 5 , the estimated costs (2007\$) for the predicted demand for ADA trips is shown in Table 8. The example below illustrates the approach. 
Table 8. Estimated Costs of Free-Fare Policy for Predicted Demand for ADA Trips

\begin{tabular}{|c|c|c|c|c|c|c|c|}
\hline Area & $\begin{array}{c}\text { Annual } \\
\text { Trips }\end{array}$ & $\begin{array}{r}\text { Range of } \\
\text { Annu }\end{array}$ & $\begin{array}{l}\text { Predicted } \\
\text { I Trips }\end{array}$ & $\begin{array}{l}\text { Cost per } \\
\text { Trip }\end{array}$ & $\begin{array}{l}\text { Current } \\
\text { Total Cost }\end{array}$ & $\begin{array}{r}\text { Range in } \mathrm{Pr} \\
\text { Cost** }\end{array}$ & $\begin{array}{l}\text { dicted Total } \\
2007 \text { \$) }\end{array}$ \\
\hline $\begin{array}{l}\text { City of } \\
\text { Chicago }\end{array}$ & $2,090,434$ & $2,529,425$ & $3,198,364$ & $\$ 32.35$ & $\$ 67,625,540$ & $\$ 81,826,903$ & $\$ 103,467,076$ \\
\hline $\begin{array}{l}\text { Suburban } \\
\text { Cook \& } \\
\text { DuPage }\end{array}$ & 404,288 & 521,532 & 691,332 & $\$ 32.10$ & $\$ 12,977,645$ & $\$ 16,741,162$ & $\$ 22,191,773$ \\
\hline $\begin{array}{l}\text { Lake, } \\
\text { Kane Will, } \\
\text { McHenry }\end{array}$ & 87,772 & 108,837 & 139,557 & $\$ 32.10$ & $\$ 2,817,481$ & $\$ 3,493,677$ & $\$ 4,479,795$ \\
\hline Total Region & $2,582,494$ & $3,159,794$ & $4,029,254$ & - & $\$ 83,420,666$ & $\$ 102,061,742$ & $\$ 130,138,644$ \\
\hline Downstate & 604,280 & 827,864 & $1,154,175$ & $\$ 26.43^{*}$ & $\$ 15,971,120$ & $\$ 21,880,435$ & $\$ 30,504,840$ \\
\hline Total Illinois & $3,186,774$ & $3,987,658$ & $5,183,429$ & - & $\$ 99,391,786$ & $\$ 123,942,177$ & $\$ 160,643,484$ \\
\hline
\end{tabular}

*weighted average

${ }^{* *}$ rounded to nearest integer

Consider the city of Chicago in Table 8 with an estimated annual ADA ridership of 2,090,434 rides. The expected demand increase due to a free-fare policy is estimated to be between 121 and 153 percent in Table 4. Therefore, the range of predicted annual ADA ridership for the city is between 2,529,425 and 3,198,364 rides. With a cost of $\$ 32.35$ per trip, the current cost is $(2,090,434 \times \$ 32.35=) \$ 67,625,540$, while the predicted annual cost is estimated to be between $(2,529,425 \times \$ 32.35=)$ $\$ 81,826,903$ and $(3,198,364 \times \$ 32.35=) \$ 103,467,076$. Similar calculations produced the rest of the figures in Table 8.

\section{Conclusions}

Occasionally, the political environment entertains policy scenarios that have direct cost implications for the provision of transit services. In such cases, transportation policy analysts may be confronted with questions that have eluded the scrutiny of academic research and industry experience. This paper tackled such a question by proposing an approach to examine the impact on demand and costs of shifting to a complementary ADA free-fare policy. In the absence of clear historical evidence, we conducted a three-pronged analysis based on relatively similar but scant industry experience, assumptions based on local knowledge, and a statistical analysis of a national model. Such an approach provides for a quick response methodology that is transferable to other locations in the country and could be implemented with limited resources. 
In doing so, the methodology complements the work conducted for TCRP Report 119 by examining the fare elasticity of demand in the neighborhood of free fare. The industry experience and local knowledge about ADA complementary operations, on the other hand, allowed us to "validate" the answers obtained from the statistical analysis. As a result, we are confident that the predicted range of impacts on demand and costs are sufficiently reasonable to use in a high-level planning analysis of "what-if" scenarios.

\section{References}

American Public Transportation Association. 1991. Effects of fare changes on bus ridership. Washington, DC. http://www.apta.com/research/info/online/elastic. cfm (accessed December 2011).

AppalCart. 2011. Fact sheet and press releases, 2006 and 2007. http://www.appalcart.appstate.edu/EN/US/ (accessed December 2011).

Chicago Transit Authority. 2011. 2005 vs. 2006 performance indicators. http:// www.transitchicago.com/news/motion/board/122046perfind4Q2006.pdf (accessed December 2011).

Dijohn, J., P. Metaxatos, L. Dirks, and K. Allen. 2008. ADA special services: Price elasticity for the provision of free service in the state of Illinois. Final report. Illinois Department of Transportation Division of Public and Intermodal Transportation. May 14, 2008.

Doxsey, L. B., and B. D. Spear (1981). Free-fare transit: Some empirical findings. Transportation Research Record 799: 47-49.

Kaye, H., S., T. Kang, and M. P. Laplante. 2000. Mobility device use in the United States: Disability statistics report. University of California, San Francisco for National Institute on Disability and Rehabilitation, June 2000.

Koffman, D., D. Lewis, D. Chia, J. Burkhardt, and M. Bradley. 2007. Improving ADA complementary paratransit demand estimation. Transit Cooperative Research Program, Report 119.

McCollom, B. E., and R. H. Pratt. 2004. Traveler response to transportation system changes: Chapter 12 - transit pricing and fares. Transit Cooperative Research Program, Report 95. 
Pace Suburban Bus. 2007. Suburban service and regional ADA budget results. Arlington Heights, Illinois, November 2007.

Perone, J. 2002. Advantages and disadvantages of fare-free transit policy. National Center for Transit Research, Report No. 473-1333. Tampa, FL., October 2002.

Perone, J., and J. Volinski. 2003. Fare, free or something in between? Center for Urban Transportation Research, University of South Florida, Tampa, FL.

Pratt, R. H. 2000. Traveler response to transportation system changes. Transit Cooperative Research Program, Web Document 12. Interim Handbook.

Regional Transportation Authority. 2007. Connecting communities through coordination: The Northeastern Illinois Coordinated Public Transit-Human Services Transportation Plan (HSTP). September, 2007, Chicago, Illinois.

Regional Transportation Authority, Chicago Transit Authority and Pace Suburban Bus Service, 2006. Regional ADA paratransit plan for persons with disabilities. January 2006, Chicago, Illinois.

Sen, A., and M. Srivastava, 1990. Regression Analysis: Theory, Methods and Applications. New York: Springer-Verlag.

Spielberg, F,. and R. H. Pratt. 2004. Traveler response to transportation system changes: Chapter 6-Demand responsive/ADA. Transit Cooperative Research Program, Report 95.

Studenmund, A. H., and D. Connor. 1982. The free-fare transit experiment. Transportation Research 15(4): 261-270.

U.S. Government Printing Office via GPO Access. 2011. Transportation Services for Individuals with Disabilities. 49CFR37, p. 440. http://www.fta.dot.gov/civilrights/ada/civil_rights_3906.html (accessed December 2011).

West, J. 1996. Implementing the Americans with Disabilities Act. Blackwell Publishing, Cambridge, MA.

\section{About the Authors}

Paul Metaxatos (pavlos@uic.edu) is Associate Director for Research Programs and Research Assistant Professor in the Urban Transportation Center, University of Illinois at Chicago. He has conducted numerous transit planning studies in Illinois. 
He most recently advised the Regional Transportation Authority in Chicago about the ridership and cost implications of an older adult free-ride program.

LISE DIRKS (Idirks1@uic.edu) is Senior Associate in the Urban Transportation Center, University of Illinois at Chicago. She specializes in GIS development and has worked on numerous transit planning studies in Illinois. 